\title{
Proactive responses to offensive behaviours in out-of-home care
}

\author{
Stephen Larmar and Julie Clark
}

\author{
Children and young people in out-of-home care \\ experience significant challenges in the adjustment \\ process. All family members are affected by the transition \\ of a child or young person into the family and so carers \\ require a unique set of skills and strategies to respond \\ appropriately. This paper is the second in a series of four \\ papers examining responses to a range of challenging \\ behaviours seen in children and young people placed in \\ out-of-home care contexts. The first paper explored \\ strategies that carers could employ to deal with \\ oppositional behaviours identified in the child or young \\ person. This paper considers offensive behaviours that \\ may be evidenced in children and young people, and \\ practical approaches which carers can utilise to respond \\ proactively to such behaviours.
}

The transition for children and young people into out-ofhome care is significantly challenging (Tilbury, Osmond, Wilson \& Clark 2007). The adjustment process can have enormous ramifications for the child/young person, particularly if they have experienced multiple placements (Newton, Litrownik \& Landsverk 2000; Sultmann \& Testro 2001). The challenges experienced by carers assisting the child or young person in their assimilation into the new environment can also be extensive (Golding 2007; Herbert $\&$ Wookey 2007). Along with the changes associated with adjusting to a new home context, individuals often arrive at the out-of-home care situation with left over stresses from previous care situations and their families of origin that can be extremely traumatic. Such stresses, as well as a range of factors that place the individual at greater risk of ongoing social and behavioural difficulties (e.g. insecure attachment, an unsafe home environment, poor social skills development), may negatively impact upon the child or young person's behaviour (AIHW 2006; Osmond, Scott \& Clark 2008).

The focus of this series on challenging behaviours in children and young people in out-of-home care prompted the authors to consider an effective model drawn from the literature that delineates a progression of antisocial behavioural responses evidenced in more at-risk individuals. A model by Edelbrock (1985) that outlines a range of antisocial behaviours that may be identified in at-risk children and young people and that lead to maladjustment in adulthood was considered. According to the model, antisocial behaviours exist on a developmental continuum from less extreme oppositional responses that may progress to offensive behaviours, aggressive behaviours and, finally, delinquent behaviours (Edelbrock 1985). Importantly, the model clearly indicates the merit of recognising and intervening with challenging behaviour early so as to interrupt the development of more entrenched and therefore difficult to change behaviours. The first paper in this series centred upon oppositional behaviours which, if uninterrupted, may lead in sequence to other more entrenched challenging behaviours. This paper focuses on offensive behaviours that may be identified in children and young people in out-of-home care contexts and provides discussion to assist carers in more effectively addressing such behaviours. 


\section{OUT-OF-HOME CARE IN AUSTRALIA}

In the last decade, there has been a significant rise in the rate of children and young people placed in out-of-home care in Australia (AIHW 2007). There are many and varied reasons why children and young people are placed in out-of-home care; however, the majority of individuals are placed in care as a result of significant abuse and neglect (Osmond, Scott \& Clark 2008). As a result of such abuse and neglect, many children and young people in out-of-home care experience significant trauma and associated mental health problems that can impact upon their psychological and emotional functioning (Larmar \& Clark 2009; Sawyer, Carbone, Searle \& Robinson 2007; Tarren-Sweeney \& Hazel 2006). The challenge for carers and health professionals is to respond in ways that contribute to the child/young person's development rather than engage in ways of responding that result in escalating punishment and/or marginalisation.

\section{For many children and young people who have been either temporarily or permanently removed from difficult family circumstances, challenging behaviours may be more extreme or occur more frequently.}

\section{OFFENSIVE BEHAVIOURS DEFINED}

Most children and young people experience challenges as part of their psychosocial development that impact upon their behaviour and socialisation within and beyond the family (Larmar 2002). Many parents and carers find themselves having to respond to particularly challenging behavioural issues from time to time as their child journeys through the infant years and on to adolescence and young adulthood (Metcalf 1997). For many children and young people who have been either temporarily or permanently removed from difficult family circumstances, challenging behaviours may be more extreme or occur more frequently. As the origins of the behaviour are often unknown, behaviour is less easily explained and may therefore make less sense to those in the child/young person's immediate environment. Some individuals may exhibit offensive behaviours within the out-of-home care context that may create pressures for the nominated carer. Edelbrock (1985) defines offensive behaviours as any behavioural response that serves the purpose of causing offence to another. Such behaviours may include responses such as fighting, swearing, overt sexual acts and disobedience in the home or school context. In particular situations, individuals behaving in an offensive manner may be choosing to be intentionally offensive as a means of eliciting a specific response in another person. In other circumstances, the individual may be behaving offensively, though their intentions are not necessarily to cause offence.

\section{THE COMPLEXITIES ASSOCIATED WITH OFFENSIVE BEHAVIOURAL RESPONSES}

For parents, teachers and other carers, one of the first steps in proactively responding to challenging behaviour in a child or young person is to understand some of the underlying causes of a specific behaviour. This may be unknown for children and young people in out-of-home care. However, carers would be well advised to check with workers in order to ensure they understand key events in the child/young person's background that may be significant. Glasser (2000) and Balson (1995) assert that all behaviour is purposeful and that there are either conscious or unconscious motivators that are driving a particular response. However, understanding the influences underlying antisocial behaviours is a complex process and requires commitment on the part of the parent/caregiver to acquiring the necessary knowledge to assist them in better understanding the child or young person and some of the reasons which explain the presence of specific behaviours. (For a further elaboration of the purposefulness of behaviour, see Larmar and Clark [2009]). Carers may choose to partake in training opportunities to help them in their capacity to care for and respond to a child/young person's needs and behavioural responses (Butcher 2004; McHugh 2002; Osmond, Scott \& Clark 2008). Training programs that are more specifically designed for foster caring such as Sharing the Care (Integrated Family and Youth Service 2009) and the Child Wise Programme (Herbert \& Wookey 2007) are helpful aids for carers. More general programs aimed at effective parenting such as Triple P (Sanders 1999), the Early Impact Program (Larmar, Dadds \& Shochet 2006), Parents Under Pressure (Dawe, Harnett, Rendalls \& Staiger 2003) and Brighter Futures (Department of Community Services 2003), as well as Parent-Child Interaction Therapy (Eyberg, Boggs \& Algina 1995) and Multi-Systemic Therapy (Cottrell \& Boston 2002), also provide helpful forums for assisting carers in the care and management of children and young people.

Like most other behaviours, the presence of offensive behaviours in an individual usually serves as an indicator of, or reaction to, environmental influences that may be impacting upon the child or young person. However, dealing effectively with offensive behaviours may be complicated given the multiple forces at play. Further, the parent/carer's perceptions of an offensive situation may be an additional barrier to a constructive response due to factors including competing value systems between the carer and 
child/young person, unrealistic carer expectations and competing concerns for other young people in the family.

Offensive behaviours are many and varied and it is important to understand that they are not always intentional. The common element of offensive behaviours is that all are governed by underlying influences that serve to meet a deeper need in the child or young person. For example, a 15year-old male may choose to act in an overtly sexual way towards his female carer as a means of deliberately offending her, like grabbing his crotch or similar rude gestures. Such a response could serve to intimidate the carer in order for the young male to assert a position of power, regardless of how socially inappropriate this form of expression may be. Alternately, a seven-year-old girl who is feeling intimidated by the carer family's older child, may choose to swear at the older child. While this behaviour may be deemed by the family to be offensive, the young girl's intentions may have been more about self-protection due to the influences of past traumatic experiences than about intentionally offending the child or family. Additionally, such a response may reflect more frequently modelled behaviour in previous care situations and so may not be intentionally offensive.

\section{Some individuals who have come from difficult circumstances ... may not be aware - and even genuinely surprised- that the behaviours they are exhibiting are actually offensive.}

Young people can sometimes choose to act offensively in order to get attention or to assert their position. For example, it is not uncommon for young people to act offensively as a means of challenging authority. Some individuals who have come from difficult circumstances, including situations of neglect, may not be aware - and even genuinely surprised that the behaviours they are exhibiting are actually offensive. A twelve-year-old boy who has been significantly abused by his birth parents and who has developed an understandable distrust of adults due to past traumatic experience, for example, may choose not to acknowledge an adult carer or respond in a respectful way. Such a position may be cause of offence for some carers. For this reason, it is of vital importance that carers make every effort to understand some of the psychosocial variables that may be impacting upon the child/young person during their transition to, and ongoing placement within, the out-of-home care context. Again, this is likely to involve talking to the child/young person's case worker and other people with knowledge of the individual (e.g. teachers, coaches, youth workers, etc.) as well as the child/young person, about how they make sense of their behaviour and what was going on for them. It is important to consider the appropriate time to talk through issues associated with behaviour as heightened emotion and the immediacy of the situation may hinder calm problem solving.

\section{A FIRST STEP: MAINTAINING CONNECTIONS WITH THE FAMILY OF ORIGIN}

Although many children and young people placed in out-ofhome care come from difficult family circumstances, the significance of maintaining links with the individual's family of origin cannot be overestimated in its contribution to creating placement stability and contributing to the individual's well-being (Fernandez 2006; Mason \& Gibson 2004; Tilbury et al. 2007; Wilson \& Sinclair 2004). It is particularly important that carers develop a greater awareness of the child or young person's circumstances prior to and during placement, including insight into the individual's family of origin (Carter 2002; Thomson 2003). Through such an understanding, carers may be able to better determine some of the motivations or influences underlying behavioural responses that may be offensive in nature. It should be noted that, while in many circumstances benefits may be derived from the child or young person maintaining contact with his/her family of origin, there may be instances in which the individual may experience further distress as a result of establishing contact with the family. For example, a child or young person who experienced significant trauma in his/her family of origin may be more likely to react negatively to further engagement with the family and, in fact, may behave offensively as a result of the distress such contact may evoke (see Larmar \& Clark [2009] for further discussion relating to the significance of connections with the family of origin).

\section{THE SIGNIFICANCE OF MODELLING AND POSITIVE COMMUNICATION}

Many children and young people in out-of-home care come from families with limited resources (AIHW 2006). A range of social complexities including low educational attainment, unemployment, poverty and its associated effects (e.g. isolation) impacts families (Thomson 2003). In such contexts, parents/carers may struggle to provide the basic necessities that ensure reasonable care (e.g. child care, health care, etc.). As a result, the child/young person may have had limited exposure to the types of interactions that serve to teach pro-social behaviours that promote healthy adjustment. While it is necessary for carers to consider the most appropriate responses to offensive behaviours in children and young people, the importance of carers being aware of their own style of interaction and consciously modelling responses, including positive communication as an initial 
first step, cannot be overestimated (Carlo, Fabes, Laible \& Kupanoff 1999).

A child/young person's language acquisition and communication skills will be compromised by inadequate stimulation and neglect. So it follows that an individual in care may lack the basic communication skills and emotional and psychological resources to assist them in engaging positively with others. For example, an individual who is chronologically adolescent may not yet have developed the same communication skills as a younger child within the carer's family as skill development is uneven. Because of this, it is imperative that they receive support in the out-ofhome care context which includes the teaching of communication skills that serve to enhance their interaction with others. One of the most effective ways to teach a child or young person communication skills is through the process of modelling (Carlo et al. 1999). Modelling essentially involves the carer and/or significant others within the home context utilising positive communication skills as a means of demonstrating to the child or young person how such skills are employed (Trotter 2006). Not only does the individual observe the ways in which family members communicate, they also see some of the benefits derived from such forms of communication which encourages them to use such skills.

\section{... one of the first steps in proactively responding to challenging behaviour in a child or young person is to understand some of the underlying causes of a specific behaviour.}

A more direct approach is to provide active instruction to assist the child or young person in understanding appropriate ways to engage with others (Sanders, Cann \& Markie-Dadds 2003). For example, the carer may explain and demonstrate turn taking behaviour to a five-year-old child who is refusing to share toys. This may be achieved by talking with the child about ways in which they can interact positively with others. Further, discussion should also focus on situations where their interaction may have been a barrier to their engagement with the family to help them see some of the differences between healthy and unhealthy responses. Using role-play may also serve to enhance such exploration and allow the individual to practice skills in a supportive space that facilitates constructive feedback and builds confidence (Larmar 2002). For example, a carer of a six-year-old child who struggles to say hello because of their mistrust of adults may facilitate practice opportunities where the child and carer can act out context-specific, imaginary scenarios to help the child practice greeting skills within a safe and supportive environment, e.g. 'What if Lucy [the child's friend] came to the door with her mother; what might you say?'.

\section{RESPONDING APPROPRIATELY TO OFFENSIVE BEHAVIOURS: SOME INITIAL CONSIDERATIONS}

When responding to offensive behaviours in a child or young person, it is important to ask some initial questions to determine some of the potential influences motivating the response (Porter 2003). For example, a particular behaviour may serve to give attention to the individual (even if it is negative attention). Alternatively, the child or young person may choose to behave in a particular way as a means of asserting power or exercising control. Often, a deeper understanding of some of the influences underlying challenging behaviours serves to assist the carer to consider the most appropriate responses to the behaviour.

It is also important to remember the significance of establishing a healthy set of boundaries that are consistently reinforced, as a proactive strategy for minimising the incidence of challenging behaviours (Sanders 1996). The use of a simple set of family rules and the consistent implementation of logical consequences for inappropriate behaviour can be helpful in teaching the child/young person reasonable behavioural expectations (see Larmar and Clark [2009] for further elaboration of this information). The establishment of age-appropriate, clear boundaries can be extremely helpful in de-escalating situations that have the potential to create stress and discourage healthy engagement.

Further, the carer should always endeavour to maintain a supportive position when responding to challenging situations (Porter 2003). Children and young people who have been exposed to traumatic family circumstances may become easily threatened by a confronting situation. Many situations may appear confronting to the child/young person (which do not appear confronting to other people who do not share the unique background of the child/young person) until they have had the opportunity to make sense of their changed circumstance. Therefore, carers must aim to communicate in a way that is both assertive, to establish clear boundaries and appropriate authority in the home, but supportive, to emphasise to the child/young person that they are safe and cared for.

Finally, there may be occasions when the carer needs to access help from others (Larmar 2002). Many children and young people who are placed in out-of-home care contexts have experienced significant abuse and neglect that may influence complex and challenging behavioural responses (Osmond, Scott \& Clark 2008). Traumatic past experiences have significant ramifications for a child or young person's mental health and can impact upon their transition into environments beyond the family of origin (Tarren-Sweeney 
\& Hazel 2006). Many individuals entering the out-of-home care context who have experienced trauma often face multiple challenges in the adjustment process (Tilbury et al. 2007). Such challenges can negatively impact upon the child or young person's behaviour, presenting ongoing challenges for carers and other health professionals (Golding 2007). For persistent behaviours that don't change or responses that are of particular concern, it may be appropriate to draw on the assistance of supportive friends or professional advice about specific behaviours evidenced in the child or young person. It is also important to be aware that there are sometimes significant risks associated with the occurrence of offensive behaviours in children and young people. For example, a child or young person engaging in an overt sexual display is likely to impact upon the safety of members of the family who have been exposed to such behaviour. In such instances, it is paramount that carers access appropriate professional help immediately. The important thing to remember is that it is OK to ask for help and to admit that you don't have all the answers.

Having highlighted a number of initial steps to take in appropriately responding to offensive behaviours, the following section delineates four scenarios that serve to demonstrate to carers some of the key considerations and strategies for responding to offensive behaviours in children and young people.

\section{... the importance of carers being aware of their own style of interaction and consciously modelling responses, including positive communication as an initial first step, cannot be overestimated.}

\section{SCENARIO ONE: 14-YEAR-OLD JAKE}

Jake entered the child protection system when he was nine years old. At the age of eight, his teacher became concerned about Jake's physical well being. Jake appeared extremely malnourished and would regularly arrive for school with no lunch. Following investigation, he was removed from his mother and stepfather and spent the next five years in multiple placements. When Jake turned fourteen, he was placed in transition to independent living. Since arriving in this new context, his carers have experienced problems with Jake's offensive behaviours at the meal table. Jake has taken to stuffing his mouth with as much food as he can, throwing food across the table and regularly 'farting' during mealtime. On the occasions when his carers have requested that he stop behaving in such a manner, Jake laughs and the behaviours escalate. His carers are at a loss to know how best to respond to Jake.

\section{Suggested response:}

A helpful first step in responding to these issues is for the carer to ask questions concerning: Jake's experience at meeting his need for food; his familiarity with regular mealtimes; what boundaries or expectations within the present context he is aware of; and what motivations might be underlying such behaviours (Glasser 2000). All of the behaviours described above appear to serve Jake's need for attention (Balson 1995). His carers may need to consider the level of attention Jake is currently receiving from them and whether they may need to give him more positive forms of attention (e.g. talking about his day/specific interests/things about his life that he feels comfortable talking about, etc.) to build a trusting and respectful relationship with him. Facilitating an honest but supportive discussion time with Jake to ascertain whether he understands the extent to which his behaviours are impacting those in his immediate environment may also assist him in reorganising his behaviours during meals. The establishment of logical consequences may also be necessary if the behaviours continue following the discussion time (Carlo et al. 1999). The most appropriate consequence would be to instruct Jake to leave the table until he is ready to return to the meal without disrupting the mealtime with his offensive responses. Before applying any consequence, however, it would be appropriate to offer Jake a warning to remind him of the agreed upon expectations regarding his behaviours during mealtimes.

\section{SCENARIO TWO: FOUR-YEAR-OLD JASMINE}

Jasmine recently entered her first out-of-home care setting just after her fourth birthday. Following investigation, Jasmine disclosed that she was being sexually abused by her mother's boyfriend. Jasmine's mother's inability to acknowledge the possibility of the abuse resulted in Jasmine being placed in out-of-home care. Jasmine's transition into the new home context has been very traumatic for her. She was placed with a middle-aged couple with adult children who no longer live at home. While Jasmine's transition into the out-of-home care context has been challenging, her carers have enjoyed her presence in their home and have noticed that Jasmine has become increasingly settled over time. A recurring issue that has been of particular concern to her carers has been Jasmine's tendency to masturbate while in the company of others (e.g. watching TV) or during occasions where she is outside the home (in her Kindy class). This has caused offence to a number of her carers' friends and family. Her carers are struggling to understand why she is engaging in this behaviour and are unsure as to how to discourage this habit. 


\section{Suggested response:}

The first consideration in this scenario is to recognise the potential influences of Jasmine's past abuse on her present behaviour (Osmond, Scott \& Clark 2008). While selfstimulation in the company of others may defy normal social boundaries, it is important to remember that, in the case of an abused child, such behaviour may be more about comfort or control than about defying a set of rules (Simms,

Dubowitz \& Szilagyi 2000). The importance of carers responding in a calm, reassuring way (e.g. low affect) without blame or judgement is critical. Consideration of the age appropriateness of new behaviour is also essential. An initial first step for the carers is to ensure that Jasmine's behaviour is explored professionally with a trained counsellor or support worker. Second, there may be times when it may be appropriate to ignore the behaviour if it is being carried out in the privacy of the carer's home (this may be difficult for a carer who finds the behaviour offensive - in this case it might be helpful for the carer to consider why the behaviour is causing them offence and to consider revising their position considering the complexities associated with sexual abuse). Third, the carer should always endeavour to approach the situation from a position of love and support to build the trust necessary to help Jasmine listen to the carer's feedback. Fourth, any feedback offered to Jasmine should be couched in age appropriate language that helps Jasmine to comprehend what is being asked of her in terms of a request for a change of behaviour. Finally, in situations where Jasmine does not respond to a simple request for a change in behaviour, the carer may need to consider removing Jasmine from the situation to prevent further offence being caused to those around her.

\section{SCENARIO THREE: 12 -YEAR-OLD SOPHIE}

Sophie was first placed in out-of-home care at the age of three. At the time of her first placement she was living with her mother, a sole parent who had a significant mental illness that impacted upon her capacity to adequately care for Sophie and her two older brothers. For the next nine years, Sophie was placed with seven different families. Sophie was recently placed with a young couple with no children. Sophie has struggled throughout her life to manage her emotional responses. She often gets angry and regularly uses inappropriate language. Her new out-of-home carers are struggling to manage her persistent swearing, particularly in social contexts where her language causes significant offence to others, including members of the church group they attend.

\section{Suggested response:}

Given Sophie's age, an appropriate initial step for the carer to take would be to talk with her at a time when she feels relaxed and in control of her emotions. Through the facilitation of a respectful conversation, the carer could help Sophie to realise that it is OK to feel angry or upset, but that it is not OK to swear at others because it may hurt or offend them. The carer could recommend Sophie employ strategies to help her understand when she is feeling angry or upset (e.g. change in physiology such as a hot head, jittery stomach, clenched fists, etc.) and then use some strategies to help her manage her anger proactively (e.g. walking away from a situation that may be threatening to her to take timeout from the situation, counting in her mind back from the numbers ten to one, visualising a calm space in her mind she can access when she is beginning to feel angry, etc.) (Smith, Lochman \& Daunic 2005). If the swearing behaviours diminish, the carer can provide encouragement to support Sophie's new position. If the behaviour continues, it may be necessary to agree with Sophie about some possible consequences that may serve as a reminder to her that it is not OK to swear or be verbally abusive (Sanders et al. 2003). A logical consequence may include requesting that Sophie leave the situation until she is prepared to speak in a respectful manner. Finally, the carer should make every effort to stay calm in situations where Sophie's behaviours may escalate. An uncontrolled, angered response from the carer would inevitably lead to an uncontrolled response in Sophie. Modelling appropriate behaviour during times of anger and stress can serve as powerful teaching tools for children and young people.

\section{The use of a simple set of family rules and the consistent implementation of logical consequences for inappropriate behaviour can be helpful in teaching the child/young person reasonable behavioural expectations.}

\section{SCENARIO FOUR: SEVEN-YEAR-OLD DYLAN}

Dylan recently entered his second out-of-home care context when his carers in his first placement were no longer able to accommodate him. He first entered the out-of-home care system when he was five years old. On turning five, Dylan's mother realised that she was no longer able to care for him and her five other children. All of the children were placed into separate out-of-home care contexts. Dylan found his first placement particularly anxiety producing given that he was separated from his elder sister Amanda. Amanda had assumed the role of primary carer during the formative years of Dylan's life. As a result of Dylan's problem behaviour, his initial carers decided they could no longer provide support for him and so he was placed in an alternative outof-home care setting. His current carers have assisted him in managing the majority of his behaviours. However, in the last few weeks he has been exposing himself at least once a 
day to the carer's thirteen-year-old daughter. They are becoming increasingly alarmed by this behaviour and are confused as to the best ways to respond to this issue.

\section{Suggested response:}

Given that Dylan's carers have seen marked improvements in his behaviour, a first step in addressing this issue would be to encourage him by identifying with Dylan the changes they have observed in his behaviour and how such changes have helped the family (Carlo et al. 1999). Second, the carers might consider some of the reasons why this behaviour is occurring. A helpful start might be to question the daughter about what might be happening prior to the behaviour occurring. If, for example, the daughter is doing something that may be contributing to the behaviour (such as purposefully annoying Dylan), then the carers may request a change in her behaviour to discourage Dylan's response. It might also be useful to think about what purpose the behaviour is serving Dylan (Glasser 2000; Porter 2003). Behaviours such as exposing one's genitals to another usually serve as a dramatic request for attention. Further, in a young person, such behaviour is usually intended to elicit a shocked or offended reaction as a means of deriving some amusement from the action. It is also important for carers to remember that, while such an act may appear overtly sexual in nature, the motivation for the behaviour may not be sexual at all. If the behaviour is serving Dylan's need for attention, it may be appropriate to encourage the daughter to ignore the behaviour in the hope that such a reaction may serve to extinguish the response (Larmar 2002). If the behaviour continued following the daughter's consistent attempts to ignore it, a common sense discussion with Dylan to help him to identify how the behaviour is inappropriate may be necessary. If after such a conversation the behaviour continued, the carers could formulate with Dylan a logical consequence that could be administered if he persisted with the behaviour. A logical response may include a verbal and written apology to the daughter as well as time out to encourage Dylan to think about the inappropriateness of his actions.

\section{A FINAL REMINDER: REMEMBER THE IMPORTANCE OF LISTENING}

While the strategies outlined above may be a constructive starting point, it is important to acknowledge the complexity and unique circumstances children and carers are negotiating. The various approaches described in each scenario provide examples that are likely to be useful in a range of situations. However, it is acknowledged that particular circumstances need to be taken into consideration (e.g. cultural appropriateness, experience of the child/young person, strengths of the carer, etc.) when responding. The importance of listening needs to be emphasised as a critical tool for working with children and adolescents (Porter
2003). For most individuals, genuine listening is a challenging skill to effectively exercise. Listening involves being conscious of the values, stereotypes and attitudes that each of us hold that influence communication. For example, views that bedwetting behaviour in a four-year-old is defiant or 'naughty' behaviour or that a five-year-old playing with food is unacceptable, need to be challenged. Attempting to understand where another is coming from by focussing on the content of what the person is saying as well as being sensitive to non-verbal cues, such as tone of voice and body language, can be a helpful 'first start' in comprehending what is going on for the person within a given context. (For further information about the significance of listening, see Larmar and Clark [2009].)

\section{CONCLUSION}

This paper has focussed on an exploration of offensive behaviours in children and young people in out-of-home care contexts. Attention was drawn to the complexities associated with offensive behavioural responses in children and young people as well as emphasis on the significance of factors motivating such behaviours, including psychosocial variables influencing the child or young person's world prior to and during placement in the out-of-home care situation. Finally, consideration was given to ways of responding to a number of more commonly identified offensive behavioural responses to assist carers to more effectively engage with, and respond to, children and young people who behave offensively.

\section{REFERENCES}

AIHW—see Australian Institute of Health and Welfare

Australian Institute of Health and Welfare (2006) Child Protection Australia 2004 - 05, Canberra. Viewed 03 June 2009, $<$ http://www.aihw.gov.au>.

Australian Institute of Health and Welfare (2007) Child Protection Australia 2005 - 06, Canberra. Viewed 03 June 2009, $<$ http://www.aihw.gov.au>.

Balson, M. (1995) Becoming better parents, $4^{\text {th }}$ edn., Melbourne: Australian Council for Educational Research.

Butcher, A. (2004) Knowledge into action! Effective practice for child and family services conference, paper presented at the ACWA Knowledge into Action conference, August, Sydney, NSW.

Carlo, G., Fabes, R.A., Laible, D. \& Kupanoff, K. (1999) 'Early adolescence and prosocial/moral behaviour II: The role of social and contextual influences', Journal of Early Adolescence, 19(2), 133 147.

Carter, J. (2002) Towards better foster care: Reducing the risks in caring for other people's children, Melbourne: The Children's Foundation.

Cottrell, D. \& Boston, P. (2002) 'Practitioner review: The effectiveness of systemic family therapy for children and adolescents', Journal of Child Psychology and Psychiatry and Allied Health, 43(5), 573 - 586. 
Dawe, S., Harnett, P.H., Rendalls, V. \& Staiger, P. (2003) 'Improving family functioning and child outcome in methadone maintained families: The Parents Under Pressure programme', Drug and Alcohol Review, 22, 299 - 307.

Department of Community Services (2003) 'Brighter Futures Program', NSW: DoCS.

Edelbrock, C. (1985) Conduct problems in childhood and adolescence: Developmental patterns and progressions, unpublished manuscript.

Eyberg, S.M., Boggs, S.R. \& Algina, J. (1995) 'Parent-child interaction therapy: A psychosocial model for the treatment of young children with conduct problem behaviour and their families' Psychopharmacology Bulletin, 31(1), 83 - 91.

Fernandez, E. (2006) 'Growing up in care: Resilience and care outcomes', in R.Flynn, P. Dudding and J.Barber (eds), Promoting resilient development in children and families, Ottawa: Ottawa University Press, $131-156$.

Glasser, W. (2000) Reality therapy in action, New York: Harper Collins Publishers.

Golding, K. (2007) 'Developing group-based parent training for foster and adoptive parents', Adoption and Fostering, 31(3), $39-48$.

Herbert, M. \& Wookey, J. (2007) 'The Child Wise Programme: A course to enhance the self-confidence and behavior management skills of foster carers with challenging children', Adoption and Fostering, 31(4), 27 - 37.

Integrated Family and Youth Service (2009) Sharing the Care Program, Queensland: IFYS.

Larmar, S.A. (2002) Encouraging positive behaviour in young children, Australia: Early Impact.

Larmar, S. \& Clark, J. (2009) 'Proactive responses to oppositional behaviours in out-of-home care', Children Australia, 34(3), 30 - 37.

Larmar, S.A., Dadds, M.R. \& Shochet, I. (2006) 'Successes and challenges in preventing conduct problems in Australian preschoolaged children through the Early Impact (EI) Program', Behaviour Change, 23(2), $121-137$.

Mason, J. \& Gibson, C. (2004) The needs of children in care - A report on a research project: Developing a model of out-of-home care to meet the needs of individual children, through participatory research which includes children and young people, Australia: University of Western Sydney.

McHugh, M. (2002) 'The costs of caring: A study of appropriate foster care payments for stable and adequate out of home care in Australia', Report prepared for the Child and Family Welfare Association of Australia, the Australian Foster Care Association and the Association of Children's Welfare Agencies, NSW: University of New South Wales.

Metcalf, L. (1997) Parenting towards solutions: How parents can use skills they already have to raise responsible, loving kids, London: Prentice Hall.

Newton, R.R., Litrownik, A.J. \& Landsverk, J.A. (2000) 'Children and youth in foster care: Disentangling the relationship between problem behaviors and number of placement', Child Abuse and Neglect, 24(10), 1363 - 1374.

Osmond, J., Scott, T. \& Clark, J. (2008) 'The knowledge of caring: Revisiting the need for knowledge support of carers', Child and Family Social Work, 13, 262 - 273.

Porter, L. (2003) Young children's behaviour: Practical approaches for caregivers and teachers, London: Paul Chapman Publishing.

Sanders, M.R. (1996) 'New directions in behavioural family intervention with children', in T.H. Ollendick \& R.J. Prinz (eds.), Advances in Clinical Child Psychology 18, New York: Plenum; 283 330.

Sanders, M.R. (1999) 'Triple P-Positive Parenting Program: Towards an empirically validated multilevel parenting and family support strategy for the prevention of behaviour and emotional problems in children', Clinical Child and Family Psychology Review, 2(2), 71 - 90.
Sanders, M.R, Cann, W. \& Markie-Dadds, C. (2003) 'The Triple PPositive Parenting Programme: A universal population-level approach to the prevention of child abuse', Child Abuse Review, 12, 155-171.

Sawyer, M.G., Carbone, J.A., Searle, A.K. \& Robinson, P. (2007) 'The mental health and wellbeing of children and adolescents in homebased foster care', Medical Journal of Australia, 186(4), 181 - 184.

Simms, M.D., Dubowitz, H. \& Szilagyi, M.A. (2000) 'Health care needs of children in the foster care system', Pediatrics, 106(4), $909-$ 918.

Smith, S.W., Lochman, J.E. \& Daunic, A.P. (2005) 'Managing aggression using cognitive-behavioral interventions: State of the practice and future directions', Behavioral Disorders, 30(3), 227 240.

Sultmann, C.M. \& Testro, P. (2001) Directions in out of home care: Challenges and opportunities, Brisbane: Peak Care Queensland.

Tarren-Sweeney, M. \& Hazel, P. (2006) 'Mental health of children in foster and kinship care in New South Wales, Australia', Journal of Paediatrics and Child Health, 42, 89 - 97.

Thomson, J. (2003) This is nothing new: Child protection concerns and poverty, Children Australia, 28(1), 4 - 10.

Tilbury, C., Osmond, J., Wilson, S. \& Clark, J. (2007) Good practice in child protection, Sydney: Pearson Education Australia.

Trotter, C. (2006) 'Child protection', in W.H. Chui \& J. Wilson (eds.), Social work and human services best practice, Federation Press: Sydney, $13-23$.

Wilson, K. \& Sinclair, I. (2004) Contact in foster care, in E.Neil and D. Howe (eds.), Contact in adoption and permanent foster care: Research, theory and practice, London: British Association for Adoption and Fostering, 165 - 183. 